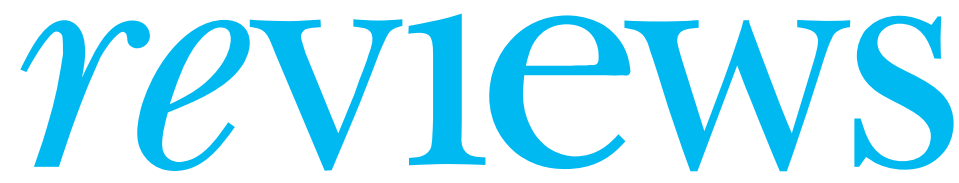

BOOKS • CD ROMS • ART •WEBSITES $\bullet$ MEDIA $\bullet$ PERSONAL VIEWS $\bullet$ SOUNDINGS

\section{The Cutter Incident: How America's First Polio Vaccine Led to the Growing Vaccine Crisis Paul Offit}

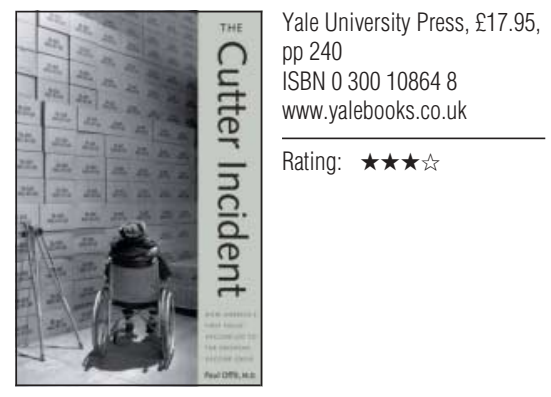

W hen I lecture medical students on immunisation, I explain that the antivaccine lobby contains few elderly people because most of them have lived through epidemics of vaccine preventable diseases such as polio or diphtheria. They have seen the devastation that these diseases can cause, and also seen them controlled by immunisation. After reading The Cutter Incident, I marvelled that most older people have maintained their confidence in immunisation despite also living through a massive and highly publicised disaster that left many crippled, and some dead, as a result of vaccine-induced polio.

Author Paul Offit, a prominent US infectious diseases physician and vaccinologist, has traced the origins of today's "vaccine crisis" to an incident during the 1950 s in which thousands of people received polio vaccine containing live polio virus. Offit describes the development of polio vaccine, from trials of early vaccines through to the appearance on the scene of Jonas Salk.

In 1951 Salk was the beneficiary of $\$ 200000$ a year for his research (a massive amount at that time), thanks to the largest public fundraising activity ever held-The March of Dimes. By this time, there were 59000 cases of polio each year in the United States. Salk undertook research on a scale never seen before. By 1954 his vaccine was ready for a clinical trial that was to include 1.8 million children: 420000 receiving the vaccine, 200000 receiving placebo, and 1.2 million receiving nothing.

The vaccine was highly effective and safe. It was licensed the next day thanks to political

Items reviewed are rated on a 4 star scale (4=excellent) pressure, and during the next two weeks, five companies distributed about five million doses. Thirteen days after the first doses were administered, there were reports of cases of polio in immunised children. All of these initial cases had received vaccine manufactured by one company-Cutter Laboratories (although vaccine made by Wyeth also caused some cases of polio). In the end, at least 220000 people were infected with live polio virus in Cutter's vaccine (including 100000 contacts of immunised children), 70000 developed muscle weakness, 164 were severely paralysed, and 10 died.

Offit outlines a series of events that contributed to vaccine containing live virus being released from Cutter Laboratories. These included the use of a highly virulent strain (Mahoney), deficiencies in the inactivation of vaccine virus, inadequate safety tests, and poor communication with other scientists and the government. However, Cutter Laboratories was doing all that the licensing authority required of it

Sixty lawsuits were subsequently filed. The first resulted in a verdict that "affected all pharmaceutical companies for the next fifty years." The jury found that Cutter was not negligent in producing the vaccine, but had breached an implied warranty that their product was safe. The concept of liability without fault was born. In other words, companies were responsible for the effects of their products even when they were not negligent in their design or manufacture.

Offit goes on to record the litany of successful lawsuits that arose from this precedent. These led to the 1986 National Vaccine Injury Compensation Program, designed to protect companies from lawsuits not supported by scientific evidence. Despite this, pharmaceutical companies are gradually abandoning vaccines. In 1957 , 26 companies made five vaccines in the United States. By 2004 four companies made 12 vaccines. Offit points out that the cost of litigation is eventually paid by the consumer and is an important contributor to the high cost of vaccines. It also prevents the development of important new vaccines.

The Cutter Incident is an enjoyable read, at times like a detective thriller, at others like a courtroom drama. Offit portrays many of the heroes-Jonas Salk and Albert Sabin, among others-as egotistical and flawed. There are some slightly irritating stylistic features-individuals and themes are repeated and re-introduced too often, the science is "dumbed down" too much on

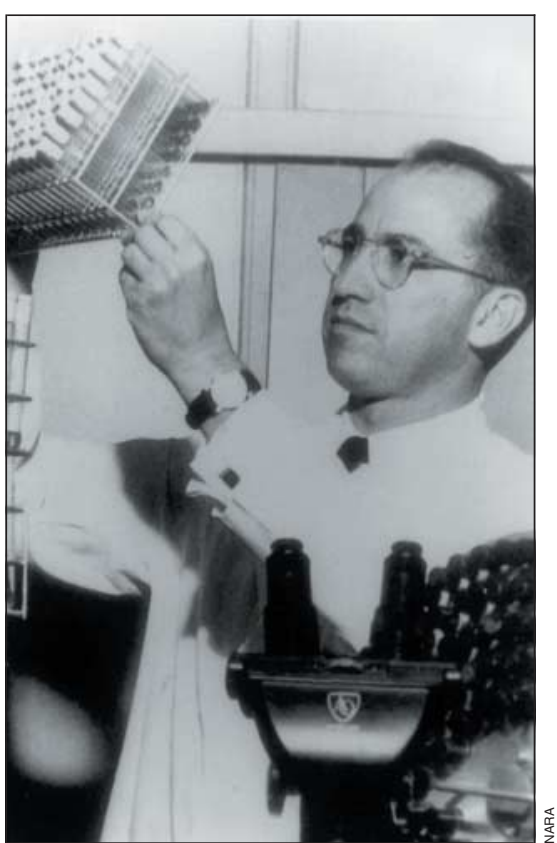

Jonas Salk

occasion, and the frequent launching into tangential stories interrupts the flow of the main plot.

Some readers may be annoyed at the particularly American perspective from which this book is written. For example, Offit portrays Sabin's oral polio vaccine as vastly inferior and downright dangerous, despite being cheap and used far more throughout the world than Salk's, and he describes the move to a two dose schedule of conjugate pneumococcal vaccine brought about by vaccine shortages in the United States as harmful (including a single example of a child who died after failure of a two dose schedule), when the evidence then and now supports the efficacy of a two dose primary schedule. But these are minor quibbles.

Like my parents and grandparents, I have been lucky enough to experience the virtual elimination of a dread disease by immunisation in my community-in my case Haemophilus influenzae type B. I tell my students that I hope they, too, will see similar things in their lifetime. The Cutter Incident reminds us how close we have been-and indeed still are-to losing immunisation as our most effective public health tool.

Jonathan R Carapetis director, Menzies School of Health Research, Casuarina, Northern Territory, Australia

jonathan.carapetis@menzies.edu.au 
Aill

\section{1 of 48}

Part of the Femininity: Sugar, Spice, all things Nice? exhibition by Sasha Consiglio at The ArtSpace, Tower Street, York, until 30 March 2006

Rating: $\star \star \star \star$

$\mathrm{S}$ asha Consiglio's 1 of 48 display is certainly more than the dolls, flowers, and pink paint that first strike the viewer. Each of the plastic female forms depicts an emotion felt by the artist's mother, retired nurse Jennifer Conway, as she progressed though the various stages of non-Hodgkin's lymphoma. The number 48 is also significant in another respect: when Mrs Conway asked for her test results in February 2003, she was told she was only one of 48 people waiting and would have to be patient.

Australian born Consiglio, who also works in a tattoo parlour, uses barbed wire, string, tape, bandages, and tentacles around the dolls' eyes, mouths, necks, arms, wrists, torsos, legs, and feet to portray Mrs Conway feeling trapped and strangled. The old dolls-some missing legs, heads, and haircome from friends, family, charity shops, and car boot sales. I had never seen so many toy

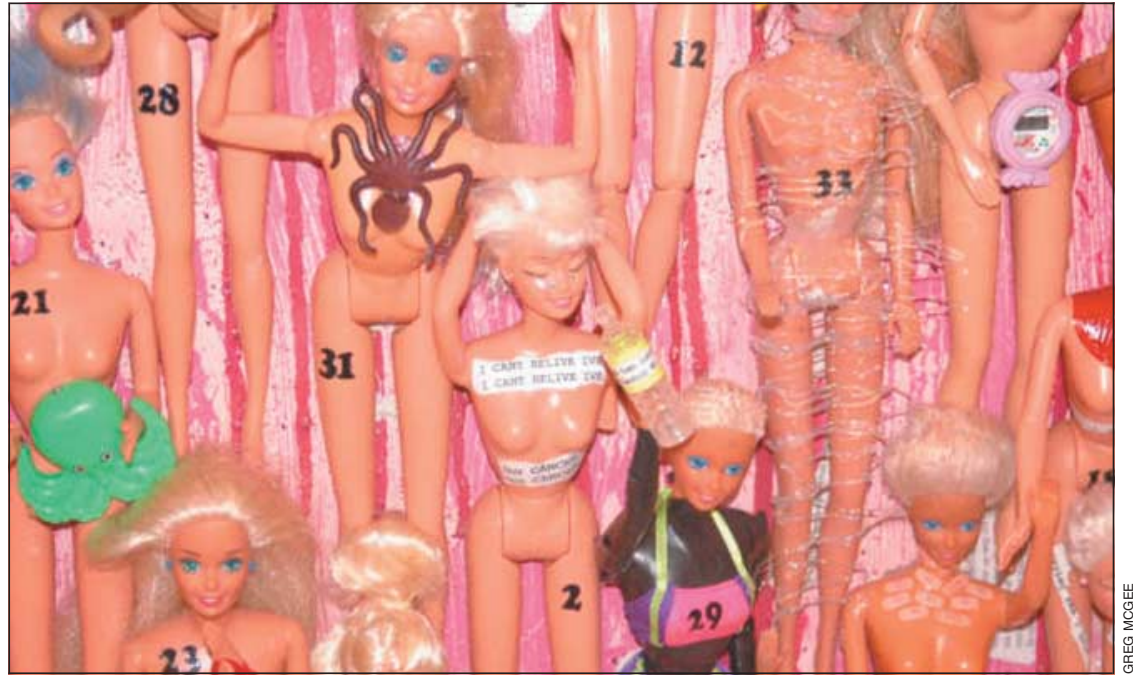

In a Barbie world

squids/octopuses before-placing them over the faces and in the hair of some of the dolls certainly had the powerful, suffocating effect Consiglio intended.

The dolls that I felt stood out most were doll 48, which, resembling Jesus on the crucifix, has nails through its hands and wire tying its feet together, and doll 11, whose upper thorax has been cut out and painted red. In general Consiglio intends the drips of red paint to symbolise shed tears rather than blood.

This is the second time 1 of 48 has been on display in York. In 2003, as part of an exhibition called Dolly Mixtures-which included 16 abandoned dolls in glass fronted baby-sized coffins-Consiglio's work was promptly removed from the bar in which it was showing after customers complained. A few of these coffins, along with another doll piece, Love $\mathrm{Me}$, are on display again now with 1 of 48 .

Jennifer Conway's lymphoma is currently in remission.

Sabreena Malik locum senior house officer and freelance medical journalist, Leeds drsabreenamalik@hotmail.co.uk

\section{$\overline{\underline{\underline{i}}}$}

\section{The Family Man}

BBC 1, starting 23 March at 9 pm

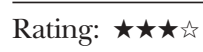

$\mathrm{O}$ the cover of this week's Radio Times is a picture of actor Trevor Eve surrounded by babies. $\mathrm{He}$ plays Patrick Stowe, a fertility expert, in a new three part series dramatising some of reproductive medicine's ethical dilemmas. "Meet the baby maker," says the caption. "Should this man play God?"

God got a couple of mentions in the first episode. Stowe jokes that a colleague "used to be a nun but decided she didn't want to do God's work any more, so she went for promotion and started doing mine" (a laboured twist on the old anti-consultant jokes). Later Stowe admits that he can't be God-but by then we don't believe him.

The title The Family Man is ironic. Stowe works to produce families for others, but his own is in disarray. Characters in television drama always have troubled home lives, but this man's emotional intelligence is unfeasibly low. His relationship with his children is toe curling. When his 15 year old son seeks affection elsewhere, Stowe examines the boy's penis, diagnoses chlamydia, and writes him a note with the address of a clinic. "Thank you, doctor," says the son, in case we miss the point.

Stowe's estranged wife remains off screen throughout. He focuses only on his work. The transference is wittily signalled when a patient, after repeated treatment failures, walks out saying: "I'm sorry, Patrick. I'm leaving you." We know she'll be back.

Ambitiously, the script interweaves the stories of four couples, each facing a different dilemma. Two of the women are being pushed by male partners to have treatment. The histories jostle in intense dialogue, and the telescoping of time causes narrative problems, but the real story is told in pictures. Like a priest, Stowe lays his hands on children's heads. The egg donor paces like a streetwalker, while the rich couple eye her up. And we see computerised accounts and piles of money.

Technical explanations are accurate, but they wash over the viewer. What grabs us is the human interest: the father's grief at the loss of a son from a family of girls; the husband falling in love with the egg donor; and the woman bus driver having a nervous breakdown at the wheel. The acting is terrific and the photography is world class, and these, more than the high tech ethics, are why we'll be watching next week.

But there is knowingness here. The character Patrick Stowe evokes the pioneer of in vitro fertilisation treatment Patrick Steptoe. Stowe's "Wishart Fertility Clinic" recalls the name of one of the surgeons struck off after the Bristol Royal Infirmary heart surgery scandal. The series' writer, Tony Marchant, has a disabled son. When one of Stowe's babies is born with Down's syndrome the doctor apologises to the mother, who brightly reassures him, but nevertheless he chooses not to add that photo to his gallery of successes.

Trevor Eve, who researched his role carefully, plays Stowe as a smoothie who is hard to like. I suppose we shall never see a leading doctor played as an amiable human being. In our post-Christian era people want doctors to take God's place and scare them.

James Owen Drife professor of obstetrics and gynaecology, Leeds

j.o.drife@leeds.ac.uk

See the web for a review of Taboo, a play about assisted conception 
PERSONAL VIEW

\section{My life as a guinea pig}

$\mathrm{L}$

ast week six young men taking part in a phase I trial in London became severely ill after being given a new drug. At least one of the volunteers who ended up in the intensive care unit at Northwick Park Hospital was using the money to pay off debts, press reports said. People in need of extra cash see medical trials as easy money. Medical students, with six years in which to build up debt, find the prospect of a large lump sum alluring. We are also considered excellent trial participants: we are young and healthy, in one place for a long time, and are not scared of hospital environments. Studies are usually advertised on hospital notice boards. They are also advertised in newspapers, with lines such as "make money in comfortable surroundings." After all, this is not work: you just have a few injections. Word spreads quickly among friends. People tip each other off with comments such as, "You're a right handed male. Go for this one. It's great money."

I have completed 16 studies over my years as a medical student, ranging from a one-off chest radiograph to a multipart trial over several months. I have regressed to childhood under hypnosis, had numerous electroencephalograms, and been told that I have a lovely gastrooesophageal junction.

But when I coughed up blood for the fourth time one morning, I thought: "Why am I doing this to myself?" I had just finished undergoing my first bronchoscopy, as part of a study looking into the effects of the cold virus on people with asthma. For three bronchoscopies and a nasty cold I would receive $£ 500$.

However, I dropped out of this study after the first bronchoscopy. I took longer than the expected one day to recover from it, and for a week I couldn't run without wheezing. I felt that the money offered to me didn't compensate for three weeks of feeling awful. The doctor running the unit was understanding and did not push me into completing the study. But I still hate the fact that I ended up as the "drop out" in their statistics and feel guilty about the time put into my work up. Would I do another trial with invasive procedures again? Maybe, but next time I would make sure I fully weighed up the benefits of the money against the potential side effects before deciding to take part.

Compensation is only for time and inconvenience, and at my university payments are capped, so that no one is tempted into studies through financial hardship. If you include time spent on travel and baseline tests, a large trial might work out at only about $£ 5$ to $£ 10$ an hour. But for about the same wage, trial participation is considerably more interesting than a supermarket job. It is never monotonous, can be written off as revision time near exam periods, and still conveys a sense of wonder about the science. Also, undergoing many of the investigations that I may have to describe to future patients is probably not a bad thing. However, it is well known among medical students that the really good money is to be found in the drug trials run by independent units.

I have never participated in a drug trial. The unknown side effects of an untested product in my body were past the limits even of my entrepreneurial spirit. But thousands of people have bronchoscopies every year The major complications have occurred enough times that their risk can actually be quantified. The extremely small risk of a perforation during bronchoscopy was one I could objectively weigh up before deciding to take part in that study. However, I would not test the HIV vaccine I saw advertised. The theoretical risk of a new HIV vaccine reverting to wild type is one that I would not be prepared to take.

One of my medical student friends took part in a drug trial for a vaccine against the human papillomavirus. The success of the trial may result in many women being protected from cervical cancer. She entered the trial from a purely altruistic motive, and for her the payment was just a bonus. She is proud that a trial she participated in has yielded such worthwhile results and, despite the potential risk to her health, would consider taking part in another trial. Indeed, many patients have benefited from the volunteers' readiness to take on risk.

From August I will finally be earning a salary, and my career as a serial trial participant will come to an end. And not before time, as my body probably needs a rest from invasive procedures-although, when I told my respiratory consultant, he haughtily informed me that in his day as a student he underwent 29 bronchoscopies for a single study, all without sedative. Perhaps medical students aren't the experimental subjects they used to be. (See News, p 683.)

Kate Mandeville final year medical student, Imperial College London kate.mandeville@imperial.ac.uk

We welcome submissions for the personal view section. These should be no more than 850 words and should be sent electronically via our website. For information on how to submit a personal view online, see http://bmi.com/cgi/content/full/325/ 7360/DC1/1
SOUNDINGS

Let's be fair about equity and equality

Both the English words equity and equality derive from the Latin aequus, meaning fair and even, yet they have assumed distinct meanings. Equality denotes evenness and the lack of difference, and has been elevated to a principle that is supposed to prevail in all domains-moral, judicial, economic, and political. Equity stands for fairness, yet what is fair is not necessarily equal, and what is equal is not necessarily fair.

Those who clamour that access to health care is a human right have, so far, eschewed declaring whether they mean that every citizen of the world ought to have equal access to health care or whether the access should merely be fair.

Everyone knows what is equal, but no one knows what, under the circumstances, is fair? Could inequality be perceived as fair? Has fairness something to do with reality, while equality is a mere construct, a mirage?

No living thing-not even a clone-is equal to another. The bell shaped curve describes variation in size, weight, talents, luck, wealth, health and life expectancy, nature and nurture, biological and social attributes, and circumstances.

It is a commonplace that access to health care is unequally distributed, and it is well known that the rich live longer, have less disability, and are likely to die in comfort. If we attempted to provide the same standard of medical care to the world's poor it would bankrupt the global economy.

It is impossible to take away from the rich the medical care that they have and redistribute it among the poor, and any attempt to do so would be to countenance the quip of Gailbraith: "If one cannot comfort the disadvantaged, one always can discomfort the privileged."

So what is fair, what is equity in access to health care? The realistic answer is: the steady improvement of health services throughout the world, in the slums of America, the disadvantaged parts of European cities, in the tottering world of the former Soviet Union, and in the developing world, everywhere.

This steady improvement will be possible only if we do not follow the pattern of contemporary Western medicine, which has become a showcase of consumerism, a hypermarket run by the industry and by the medical establishment.

Imre Loefler editor, Nairobi Hospital Proceedings, Kenya 